\title{
QTL underlying resistance to two HG types of Heterodera glycines found in soybean cultivar 'L-10'
}

Wei Chang ${ }^{1 \dagger}$, Limin Dong ${ }^{1 \dagger}$, Zizhen Wang ${ }^{1}$, Haibo Hu${ }^{1}$, Yingpeng Han ${ }^{1}$, Weili Teng ${ }^{1}$, Hongxia Zhang ${ }^{2}$, Maozu Guo ${ }^{3}$ and Wenbin $\mathrm{Li}^{1^{*}}$

\begin{abstract}
Background: Resistance of soybean (Glycine max L. Merr.) cultivars to populations of cyst nematode (SCN; Heterodera glycines I.) was complicated by the diversity of HG Types (biotypes), the multigenic nature of resistance and the temperature dependence of resistance to biotypes. The objective here was to identify QTL for broadspectrum resistance to SCN and examine the transcript abundances of some genes within the QTL.

Results: A Total of $140 F_{5}$ derived $F_{7}$ recombinant inbred lines (RILs) were advanced by single-seed-descent from a cross between 'L-10' (a soybean cultivar broadly resistant to SCN) and 'Heinong 37' (a SCN susceptible cultivar). Associated QTL were identified by WinQTL2.1. QTL Qscn3-1 on linkage group (LG) E, Qscn3-2 on LG G, Qscn3-3 on LG J and Qscn14-1 on LG O were associated with SCN resistance in both year data (2007 and 2008). Qscn14-2 on LG O was identified to be associated with SCN resistance in 2007. Qscn14-3 on LG D2 was identified to be associated with SCN resistance in 2008. Qscn14-4 on LG J was identified to be associated with SCN resistance in 2008. The Qscn3-2 on LG G was linked to Satt309 (less than 4 cM), and explained $19.7 \%$ and $23.4 \%$ of the phenotypic variation in 2007 and 2008 respectively. Qscn3-3 was less than 5 cM from Satt244 on LG J, and explained 19.3\% and 17.95\% of the phenotypic variations in 2007 and 2008 respectively. Qscn 14-4 could explain $12.6 \%$ of the phenotypic variation for the SCN race 14 resistance in 2008 and was located in the same region as Qscn3-3. The total phenotypic variation explained by Qscn3-2 and Qscn3-3 together was 39.0\% and 41.3\% in 2007 and 2008, respectively. Further, the flanking markers Satt275, Satt309, Sat_350 and Satt244 were used for the selection of resistant lines to SCN race 3, and the accuracy of selection was about $73 \%$ in this RIL population. Four genes in the predicted resistance gene cluster of LG J (chromosome 16) were successfully cloned by RT-PCR. The transcript encoded by the gene Glyma16g30760.1 was abundant in the SCN resistant cultivar 'L-10' but absent in susceptible cultivar 'Heinong 37'. Further, the abundance was higher in root than in leaf for 'L-10'. Therefore, the gene was a strong candidate to underlie part of the resistance to SCN.
\end{abstract}

Conclusions: Satt275, Satt309, Sat_305 and Satt244, which were tightly linked to the major QTL for resistance to SCN on LG G and J, would be candidates for marker-assisted selection of lines resistant to the SCN race 3. Among the six RLK genes, Glyma16g30760.1 was found to accumulate transcripts in the SCN resistance cultivar 'L-10' but not in 'Heinong 37'. The transcript abundance was higher in root than in leaf for L-10.

\footnotetext{
* Correspondence: wenbinli@neau.edu.cn

+ Contributed equally

'Soybean Research Institute (Key Laboratory of Soybean Biology of Chinese

Education Ministry), Northeast Agricultural University, Harbin, 150030, China

Full list of author information is available at the end of the article
} 


\section{Background}

Soybean (Glycine max (L.) Merr.) is the most important economic and nutritional legume crop for both oil and protein products worldwide [1]. However, a variety of abiotic stresses and biotic stress are threatening the world's soybean production every year. After scarcity of water, seed yield losses in soybean are mainly due to pest and pathogen infections [2]. One of the most destructive pests of soybean is the soybean cyst nematode (SCN; Heterodera glycines Ichinohe). It can cause various symptoms after infection such as chlorotic patches within leaflets, root necrosis and suppression of root growth. Yield losses in the world due to SCN infection have approached $\$ 2$ billion a year [3]. Once established in a field, the infestations have been difficult to eradicate. Eight races of SCN are found (1, 2, 3, 5, 6, 7, 9 and 14) [4] in China. Race 3 is predominant in the Northeastern Provinces of China (including Heilongjiang, Jilin, Liaoning and Inner Mongolia).

Although biological controls and transgenic technology have some promise, breeding the pest-resistant materials was still the only effective control method by 2010 [5]. There were more than 100 soybean accessions from Asia that contained SCN resistance genes, but only a few of them had been utilized for developing US cultivars and nearly all the resistance genes in developed varieties were from two sources, 'Peking' and 'PI88788' [6].

Inheritance of resistance to SCN was first reported in Peking when three resistance genes (rhg1,rhg2 and rhg3) were identified [7]. The rhg1 locus has been shown to have the greatest impact on the development of SCN from all HG Types in several resistance sources including Peking, PI437654 and PI88788. Although originally reported as a recessive locus, the rhg1 locus has more recently been characterized as incomplete dominant or dominant depending on the HG Type 0 used [8]. The fourth resistance gene $R h g 4$ had been confirmed as being necessary for full resistance to some races of SCN in Peking but not PI88788. It behaved as a dominant gene in Peking-derived sources. Both Rhg1 and Rhg4 were necessary for the full resistance to SCN race 3 and 14. An additional dominant gene was identified in PI88788 and was designated Rhg5 that also had been characterized as a dominant gene [9].

HG Types and plant resistance were both shown to be temperature dependent. As the traditional breeding process is time consuming and labor intensive, new cultivar breeding usually could not adapt with the speed of drift among pathogen populations driven by mutations within massive field populations. Therefore, new methodologies for $\mathrm{SCN}$ resistance breeding were required. Genetic marker technology has facilitated the identification, localization and characterization of QTL associated with important agronomic traits including SCN resistance [7]. DNA-based techniques such as micro satellites (SSR) have been used extensively for soybean gene mapping, because they are abundant, uniformly distributed, highly polymorphic, codominant, rapidly produced by PCR, relatively simple to interpret, and easily accessed by other laboratories via published primer sequences. Further, they have been used to anchor the soybean genome sequence [10]. Consequently, numerous publications have appeared on the identification and localization of QTL underlying resistance to SCN [7]. The marker assisted selection provided the potential to develop SCN resistance in soybean cultivars tested in single environments, often in greenhouse assays. For instance, Soybean JTN-5503, JTN-5303 (high yield, with resistance to multiple nematode populations), were the first soybean lines developed using MAS for nematode resistance $[11,12]$.

The SCN resistance gene $R h g 4$ was inferred to be linked with pBLT24, pBLT56 and $I$ gene for seed coat color on linkage group A2 (chromosome 8) [13]. QTL identified and localized for SCN resistance based on both genotypic and phenotypic data in a segregating population was first reported by Concibido et al. (1994) [14]. During the following decade, a total of $60 \mathrm{SCN}$ resistant QTL were reported on the following linkage groups: A1, A2, B1, B2, C1, C2, D1a, D2, E, F, G, H, I, J, L, M, and N [7]. QTL on the LG G near rhg1 was detected in most studies and was considered to be one of the major genes underlying resistance to SCN. Nearly $80 \%$ of these studies used the SCN HG Type 0 (race 3) resistance because it was the main cause of yield reduction among soybeans grown in many areas, including Northeast of China. A minor QTL S16-5 on LG K provided $5 \%$ additive effects for resistance to $S C N$ race 1 had been reported in 2009, this was the first report of a QTL on linkage group K associated with SCN resistance [15]. Another QTL was detected on LG D2 (Satt574; P $=0.001, \mathrm{R} 2=11 \%$ ) and associated with the resistance to HG Types 1.3- and 1.2.5- [6].

Candidate genes underlying QTL were identified and one, a lecine-rich repeat (LRR) trans-membrane (TM) receptor like kinase (RLK) was tested in transgenic plants [8]. Resistance was provided to SCN and a fungal pathogen, Fusarium virguliforme. In contrast, another RLK in the Rhg4 interval was shown not to underlie the resistance locus [16]. Candidate genes underlying other loci were not reported to date.

Cultivars with broad-spectrum resistance to SCN were available in China and may be more useful than those that had specific resistance. 'Heinong 37' was shown to be genetically distinct from SCN resistant cultivars with high yielding under continuous culture [17]. 'L-10' was resistant to different races of SCN (by our unpublished 
data). The objectives of the present study were to confirm the previously reported QTL, to identify new QTL associated with broad-spectrum resistance to multiple $\mathrm{SCN}$ races and to examine candidate genes underlying selected QTL using the cross of 'Heinong 37' and 'L-10'.

\section{Results}

\section{Linkage Analysis}

A total of 711 SSR markers were used for detecting polymorphisms between the two parents, and 211 of them $(29.7 \%)$ were polymorphic among the RILs. It was remarkable that the ratio of polymorphic markers was extremely high on LG G and LG J (about 53\% and $50 \%)$. A total of 151 SSR markers that were polymorphic among RILs were mapped onto the integrated soybean linkage map designed by Song et al. [18]. Chi-square tests of these markers fitted well the expected ratio of 1:1 for genotypes AA: BB.

\section{Female index analysis based on the greenhouse data}

The female index was significantly different between the two parents, 'L-10' (mean 0.8\%) and 'Heinong 37' (mean 79.9\%). The mean female index across the RIL population was 48.8 to 109.2 for race 3 and 38.1 to $43.3 \%$ for race 14 in 2007 and 2008, respectively. The range of female index for the race 3 was much wider than that for the race 14 in both 2007 and 2008 (Table 1). The Shaprio-Wilks tests showed that the frequency distribution of female index significantly deviated from normal distribution model $(\mathrm{W}=0.830, \mathrm{P}<0.0001$ for race 3 in 2007; $\mathrm{W}=0.822, \mathrm{P}<0.0001$ for race 14 in $2007 ; \mathrm{W}=$ $0.891, \mathrm{P}<0.0001$ for race 3 in $2008 ; \mathrm{W}=0.80, \mathrm{P}<$ 0.0001 race 14 in 2008). However, using the SAS normal logarithm conversion of the data resulted in normal distributions for these female index data (race 3 in 2007: $\mathrm{W}=0.92, \mathrm{P}=0.2274$; race 14 in $2007: \mathrm{W}=0.91, \mathrm{P}=$ 0.1897; race 3 in 2008: $\mathrm{W}=0.92, \mathrm{P}=0.3544$; race 14 in 2008: $\mathrm{W}=0.94, \mathrm{P}=0.2679$ ) (Figure 1 ).

\section{QTL analyses based on the greenhouse loss data}

The map distance between molecular markers and the associated QTL were calculated by WinQTL 2.1. QTL were relevant to $\mathrm{SCN}$ resistance based on the greenhouse female index data in this study (Figure 2). QTL Qscn3-1 on MLG E was detected in the interval Satt573-Satt268 that explained $11.36 \%$ and $7.14 \%$ of the phenotypic variation for SCN race 3 resistance in 2007 and 2008. A major QTL, Qscn3-2, was located on MLG G in the interval Satt275-Satt309 and accounted for $19.73 \%$ and $23.36 \%$ of the phenotypic variation for SCN race 3 resistance in 2007 and 2008, respectively. On MLG J, Qscn3-3 was detected in the interval Sat_350Satt244 that explained $19.3 \%$ and 17.95 of the phenotypic variation for SCN race 3 resistance in 2007 and
2008, respectively. In the same interval, QTL Qscn14-4 was mapped approximately $3.3 \mathrm{cM}$ from the marker Satt 244 and accounted for $12.62 \%$ of the phenotypic variation for $\mathrm{SCN}$ race 14 resistance in 2008. There were two QTL-Qscn14-1 and Qscn14-2 for SCN race 14 resistance were detected on MLG O in the intervals Satt345-Satt259 and Satt153-Satt550 that explained $8.84 \%$ and $4.97 \%$ of the phenotypic variance in both years, and $15.14 \%$ in 2007. QTL Qscn14-3 accounting for $6.8 \%$ of the phenotypic variation was found on MLG D2 between Satt082 and Satt514 for SCN race 14 resistance in 2008 (Table 2).

The flanking markers Sat_350 and Satt244 could be used for the selection of the QTL that underlay both resistances to $\mathrm{SCN}$ race 3 and $\mathrm{SCN}$ race 14 . The total phenotypic variation explained by Qscn3-2 and Qscn3-3 together was $39.0 \%$ and $41.3 \%$ for the year 2007 and 2008, respectively. Further, the flanking markers Satt275, Satt309, Sat_350 and Satt244 were used for the selection of resistant lines to $\mathrm{SCN}$ race 3. The accuracy of selection was about $73 \%$ in this RILs population from the cross between 'L-10' and 'Heinong 37' (data not shown).

\section{Candidate gene detection and transcript abundance analysis}

All the QTL mentioned above were projected on the genetic map GmComposite2003 based on the homothetic function. For the interval between Sat_350 and Satt244 that contained the genes underlying resistance to both $\mathrm{SCN}$ race 3 and SCN race 14, the QTL was first projected on the genome map according to the physical distance ratio of genetic distance of $412 \mathrm{kbp} / \mathrm{cM}$ between the two DNA markers. A total of 343 putatively gene encoded sequences encompassed in this region were used for resistance gene analog (RGA) detection by the hmmsearch program. Six encoded sequences were considered to be candidate SCN R-genes (Figure 3 ). According to the conversed domain shared by all the $\mathrm{R}$-genes, all of these six encoded sequences were identified to encode LRR-TM-PK protein [8]. It was notable that these encoded sequences were organized in a cluster on the chromosome 16 (inferred to be LG J). Four encoded sequences within this cluster of chromosome 16 were successfully amplified by RT-PCR and showed a high homology with other LRR-TM-PK type of resistance genes (data not shown). The results of semi-quantitative RT-PCR showed that Glyma16g30760.1 was only abundant in the SCN resistant cultivar 'L-10' but not in susceptible 'Heinong 37'. Further, the transcript abundance was higher in root than in leaf for 'L-10'. Therefore, the gene might play a role in the $\mathrm{SCN}$ resistance (Figure 4). Future analyses would be focused to determine the role in the resistance mechanism underlain by Glyma16g30760.1. 


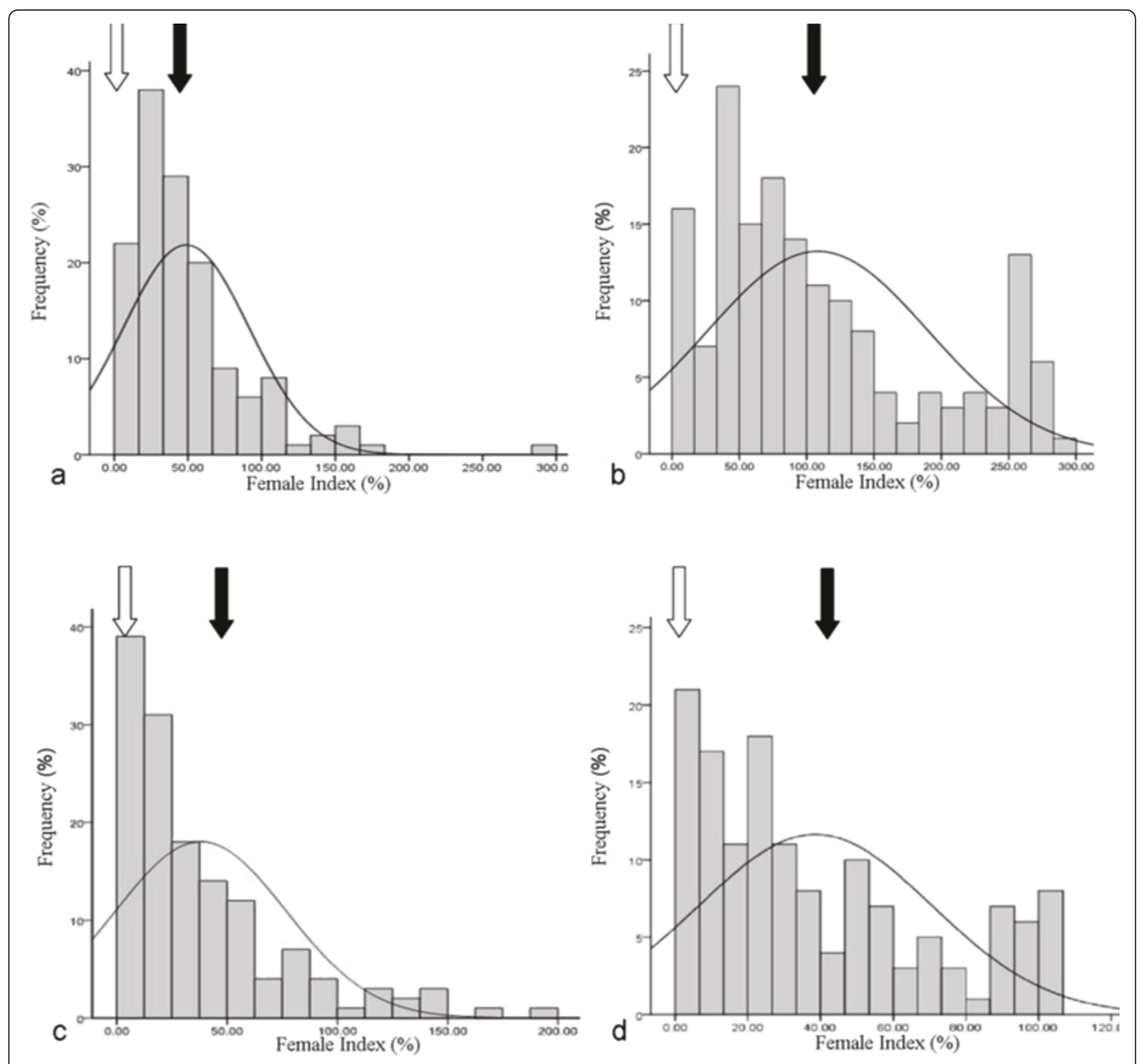

Figure 1 Distribution of Female Index among 140 RILs. Filled arrows represent mean values for the RILs, empty arrows respresent mean values for 'L-10'. a: SCN race 3 in 2007, b: SCN race 3 in 2008, C: SCN race 14 in 2007, d: SCN race 14 in 2008.

Table 1 The mean percentage of SCN female index for parents and RILs inoculated with different SCN races in the greenhouse

\begin{tabular}{lllll}
\hline SCN races & FI of 'L-10' & FI of 'Heinong $\mathbf{3 7}^{\prime}$ & Average FI in RILs & The FI Range in RILs \\
\hline $07-03^{\text {a }}$ & 0.6 & 56.4 & 48.8 & $0-291.0$ \\
$07-14^{b}$ & 1.6 & 80.3 & 38.1 & $0-190.9$ \\
$08-03^{c}$ & 0.0 & 94.3 & 109.2 & $0-284.0$ \\
$08-14^{\text {d }}$ & 1.1 & 88.6 & 43.4 & $0-106.3$ \\
\hline
\end{tabular}

${ }^{a}$ 07-03: RILs inoculated with the SCN race 3 in 2007; ${ }^{\mathrm{b}}$ 07-14: RILs inoculated with the SCN race 14 in 2007; ${ }^{\mathrm{c}}$ 08-03: RILs inoculated with the SCN race 3 in 2008; d 07-03: RILs inoculated with the SCN race 14 in 2008; FI = (Number of cysts and females on detected plant)/(Average number of cysts and females on 'Lee68') $\times$ 100. 


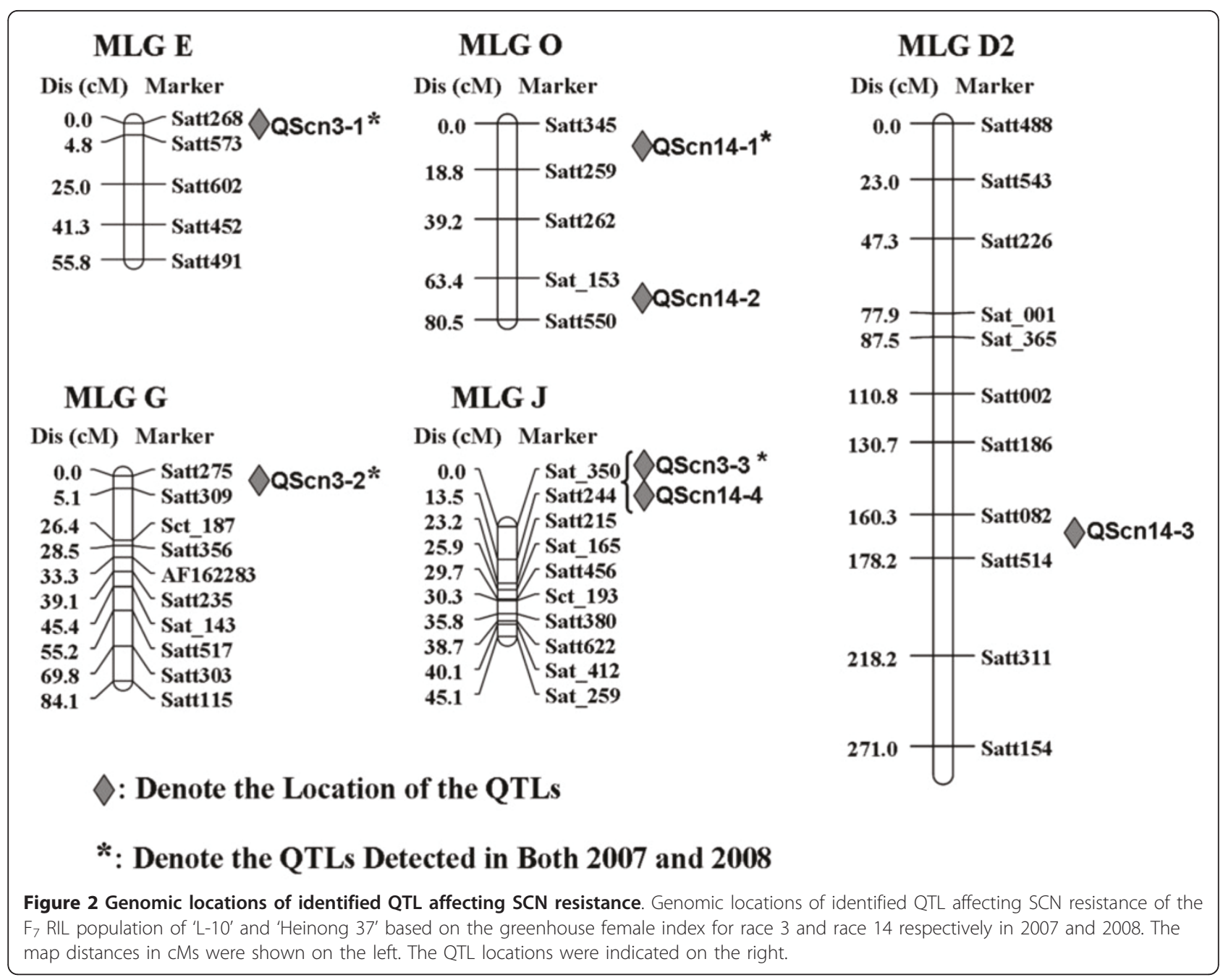

\section{Discussion}

The SCN resistance line 'L-10' had a broad-spectrum resistant to $\mathrm{SCN}$. There was great interest in transferring the SCN resistance of this cultivar into other cultivars. Traditional identification processes were time consuming and labor intensive. Increasing the selection intensity by marker-assisted selection of genotypes and subsequently more limited phenotypic selection will lead to improved the selection gains.

Segregation distortion had been reported repeatedly in soybean inbred line populations segregating for the soybean cyst nematode resistance locus rhg1, but the frequency of the SCN resistance allele was lower than expected [19]. In this study, QTL Qscn3-2 that was within the same region as the rhg1 locus was only detected in about one fourth of the population based on the flanking markers Satt275 and Satt309. The flanking markers Sat_350 and Satt244 for Qscn3-3 were only detected in nearly one third of the population. It was reported by Kopisch-Obuch et al. (2006) that the association between the resistance allele and reduced field emergence contributed to the segregation distortion at the SCN resistance loci [19]. In contrast, Webb et al. (1995) reported that either gametic or zygotic selection driven by a second locus on LG $M$ that had to be inherited in phase were responsible [20]. In the present study, the RIL population performed a Skewness distribution due to non-typical quantitative trait of cyst nematode resistance. However, using the SAS normal logarithm conversion of the data resulted in normal distributions for these female index data, which could be used for QTL mapping.

Two major QTL (Qscn3-2 on LG G and Qscn3-3 on LG J) were identified to be significantly associated with the resistance to $\mathrm{SCN}$ race 3. The two QTL jointly explained about $40 \%$ of the total phenotypic variation. The QTL Qscn3-2 fell within a similar marker interval (Satt275-Satt309) previously reported associated with resistance to $\mathrm{SCN}$ race 3 . This region was considered to be the rhg1 locus. The rhg1 locus had been shown to have an impact on SCN development in several 


\section{MLG J}

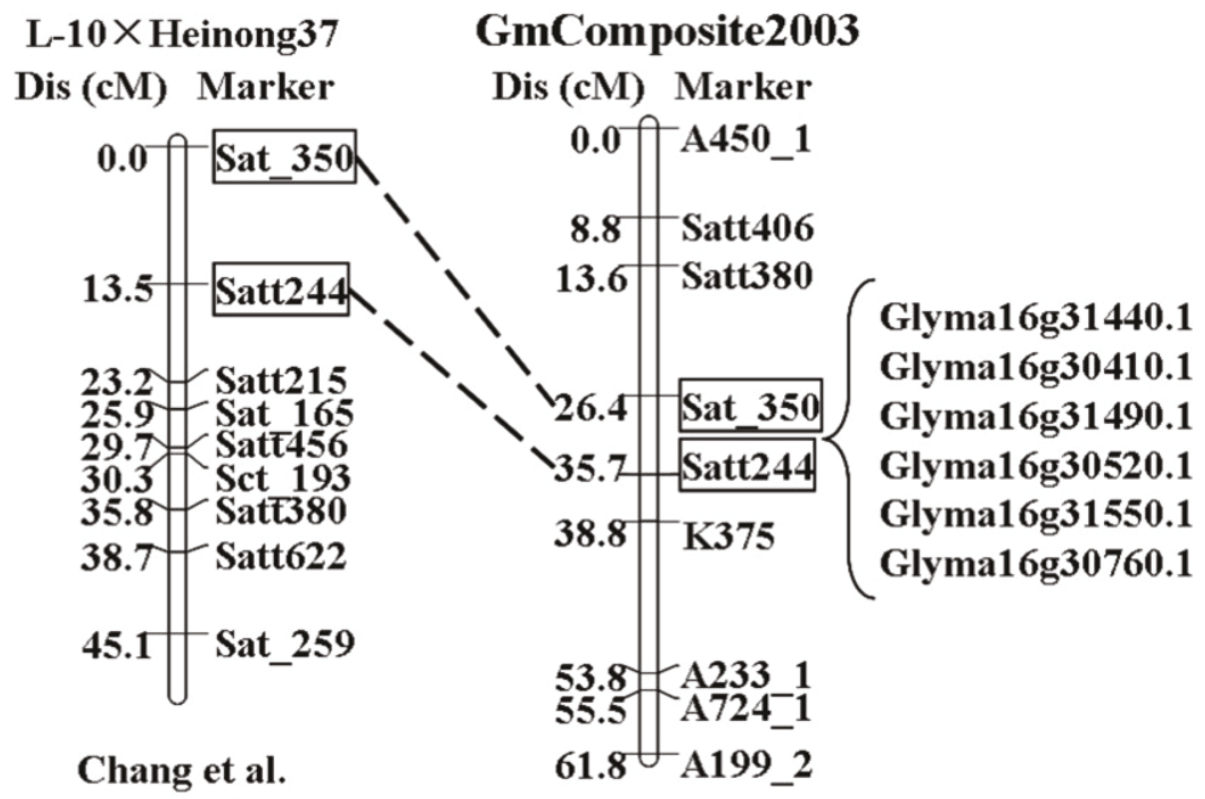

This Study

\section{Song et al.}

(2004)

Figure 3 Projecting and genetic map integration of MLG J. The markers framed were common markers of these two maps. The map distances in CMs were shown on the left. The QTL locations were indicated on the right.

resistance lines and provided resistance to many common SCN populations such as race 3 and 14. Many research groups have mapped the rhg1 locus on chromosome 18 , to a location approximately $0.4 \mathrm{cM}$ from Satt309 [21,22].

The interval on LG J contained both Qscn3-3 and Qscn14-4 (including rhg5) might underlie multi-races resistance to $\mathrm{SCN}$ in soybean [14]. In this study, no QTL was identified on the LG A2. The Rhg4 locus was considered to be another main QTL for SCN resistance, tightly linked to $I$ locus [13]. Four alleles were known at $I$, the dominant allele inhibited seed coat pigmentation, leading to possession of a yellow seed coat, whereas the recessive $\mathrm{i}$ allele conferred a pigmented seed coat. Two

Table 2 Markers associated with SCN resistance based on the greenhouse female index data

\begin{tabular}{|c|c|c|c|c|c|c|c|c|c|}
\hline \multirow[t]{2}{*}{ QTL } & \multirow[t]{2}{*}{ MLG } & \multirow[t]{2}{*}{ Years } & \multirow[t]{2}{*}{ Interval } & \multirow[t]{2}{*}{ Marker } & \multirow[t]{2}{*}{ Dis (cM) } & \multirow[t]{2}{*}{$R^{2}(\%)^{a}$} & \multirow[t]{2}{*}{$\operatorname{LOD}^{b}$} & \multicolumn{2}{|c|}{ Allelic means $\pm \mathrm{SEM}^{\mathrm{c}}$} \\
\hline & & & & & & & & $\mathrm{L}-10$ & Heinong37 \\
\hline Qscn3-1 & $E$ & 2007 & Satt573-Satt268 & Satt573 & 2.65 & 11.36 & 3.0788 & $15.35 \pm 6.32$ & $65.56 \pm 9.22$ \\
\hline Qscn3-1 & $E$ & 2008 & Satt573-Satt268 & Satt573 & 2.26 & 7.14 & 2.0428 & $19.21 \pm 10.22$ & $86.36 \pm 9.26$ \\
\hline Qscn3-2 & G & 2007 & Satt275-Satt309 & Satt309 & 3.14 & 19.73 & 3.3728 & $10.21 \pm 5.27$ & $68.44 \pm 8.12$ \\
\hline Qscn3-2 & G & 2008 & Satt275-Satt309 & Satt309 & 3.92 & 23.36 & 2.3952 & $12.23 \pm 5.42$ & $90.12 \pm 10.39$ \\
\hline Qscn3-3 & $J$ & 2007 & Sat_350-Satt244 & Satt244 & 4.3 & 19.3 & 2.5631 & $19.36 \pm 12.36$ & $63.92 \pm 5.97$ \\
\hline Qscn3-3 & $J$ & 2008 & Sat_350-Satt244 & Satt244 & 2.6 & 17.95 & 3.0245 & $19.65 \pm 5.36$ & $85.17 \pm 11.45$ \\
\hline Qscn14-1 & $\mathrm{O}$ & 2007 & Satt345-Satt259 & Satt345 & 9.96 & 8.84 & 2.5374 & $24.97 \pm 7.09$ & $60.67 \pm 9.19$ \\
\hline Qscn14-1 & $\mathrm{O}$ & 2008 & Satt345-Satt259 & Satt346 & 7.39 & 4.97 & 2.2664 & $21.17 \pm 15.32$ & $88.6 \pm 12.69$ \\
\hline Qscn14-2 & 0 & 2007 & Satt153-Satt550 & Satt550 & 11.27 & 15.14 & 4.1175 & $19.32 \pm 11.51$ & $70.83 \pm 15.78$ \\
\hline Qscn14-3 & $\mathrm{D} 2$ & 2008 & Satt082-Satt514 & Satt082 & 1.27 & 6.8 & 2.4523 & $16.39 \pm 6.69$ & $73.92 \pm 11.58$ \\
\hline Qscn14-4 & J & 2008 & Sat_350-Satt244 & Satt244 & 3.3 & 12.62 & 2.0563 & $17.63 \pm 9.18$ & $68.29 \pm 10.63$ \\
\hline
\end{tabular}

${ }^{a} R^{2}$ was the proportion of the phenotypic data explained by the marker locus; ${ }^{b}$ LOD was log of odd score; ${ }^{\mathrm{c}} \mathrm{SEM}$ (standard error mean): SD $\sqrt{ } \mathrm{N}$ where $\mathrm{SD}$ was standard deviation and $\mathrm{N}$ was the number of each of allele. 


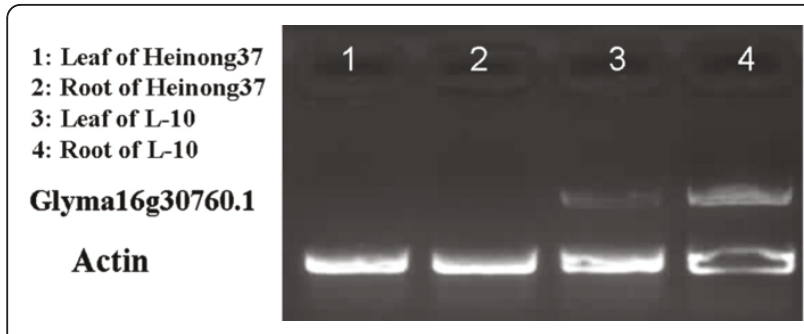

Figure 4 Result of semi-quantitative RT-PCR for Glyma16g30760.1 transcript abundance. Actin: an internal standard $\beta$-actin.

other alleles, $\mathrm{i}^{\mathrm{i}}$ and $\mathrm{i}^{\mathrm{k}}$, gave rise to restricted pigmentation of the hilum and the saddle-shaped region, respectively [23]. In our work, there was no significant correlation between the color of seed coat (or hilum) and SCN resistance. This result indicated that the line ' $\mathrm{L}-10$ ' had another locus for resistance to $\mathrm{SCN}$ race 3 independent of the Rhg4 locus. This locus may be similar to the LG J locus found in PI 88788 [7].

The SCN resistance alleles were previously associated with maturity, plant height, and lodging scores [19]. In contrast there were some rhg1 SCN resistance alleles from G. soja either had no effect or significantly $(\mathrm{P}<$ 0.05 ) enhanced yield compared with the susceptible alleles [24]. Here the correlation analysis suggested that some morphological traits such as plant height, color of pod coat, 100-seed weight and maturity were significantly associated with SCN resistance. Soybeans with tall stems, large seed size, late maturity and low protein content were correlated with $\mathrm{SCN}$ resistance for both race 3 and 14 ( $\mathrm{P}<0.05)$. The use of the ' $\mathrm{L}-10$ ' $\mathrm{SCN}$ resistance loci would provide breeders with an alternative source of SCN resistance that was not associated with reduced yield.

Two SSR markers, Satt275 and Satt309 on MLG G, were tightly linked to the major QTL Qscn3-2. Sat_305 and Satt244 on MLG J were tightly linked to the QTL Qscn3-3 and Qscn14-4. The total phenotypic variation explained by Qscn3-2 and Qscn3-3 together was 39.0\% and 41.3\% for the year 2007 and 2008, respectively, and these four markers had potential use for marker-assisted selection of lines resistant to the $\mathrm{SCN}$ race 3 . It was showed that nearly $80 \%$ of lines with the alleles of these four markers that were contributed by 'L-10' provided high resistance or completely immunity $(\mathrm{FI}=0)$. As the rhg1 locus has been characterized as incompletely dominant, soybean lines heterozygous at this locus often allowed cyst formation at a rate intermediate between the genotype of homozygous resistant and homozygous susceptible [14,25]. Here some lines were still heterozygous at the rhg1 locus after MAS, suggesting a more accurate gene based selection was needed for the greater accuracy $[8,26]$.
Qscn14-4 might underlie multi-races resistance in soybean. Kanazin et al. (1996) identified a gene cluster that contained eight RGAs on LG J in the similar region [27]. Further, six members of the RLK family were involved in one cluster on Chromosome J. Among these the RLK gene Glyma16g30760.1 was found to accumulate transcripts in the SCN resistance cultivar ' $\mathrm{L}-10$ ' but not in 'Heinong 37' and the transcript abundance was higher in root than in leaf for 'L-10', suggesting that the gene might play a role in the $\mathrm{SCN}$ resistance to race 3 and race 14. Melito et al. (2010) suggested that the RLK at rhg1 was involved in root development but not nematode development as shown by others [25]. Unfortunately, the study of Melito et al. (2010) was flawed by the lack of an analysis of the target RLK protein abundance despite the available antibodies. Further studies of the RLKs at rhg1 and rhg5 will be needed for the clarification of the resistance mechanism and involvement of the candidate genes.

Glyma16g30760.1 was tightly linked to the QTL Qscn3-3 and Qscn14-4, indicating that this gene might be associated with both $\mathrm{SCN}$ race 3 and race 14 resistance. Therefore, a real-time PCR combined with molecular marker-based selection could be used for the future breeding of SCN resistant lines.

\section{Conclusions}

The four main SSR markers, Satt275, Satt309, Sat_305 and Satt244, which were tightly linked to the major QTL for resistance to SCN on LG G and J, would be candidates for marker-assisted selection of lines resistant to the SCN race 3. Among the six RLK genes, Glyma16g30760.1 was found to accumulate transcripts in the SCN resistance cultivar ' $\mathrm{L}-10$ ' but not in 'Heinong 37'. The transcript abundance was higher in root than in leaf for 'L-10', suggesting that the gene might play a role in the SCN resistance to race 3 and race 14 .

\section{Methods}

\section{Construction of population and isolation of SCN}

The $140 \mathrm{~F}_{5}$ derived $\mathrm{F}_{7}$ recombinant inbred lines (RILs) were advanced by single-seed-descent from a cross between 'L-10' and 'Heinong 37'. 'L-10' was a soybean line broadly resistant to $\mathrm{SCN}$ developed by Northeast Agricultural University, Harbin, China and 'Heinong 37' was a SCN susceptible cultivar that had high yield in un-infested environments. The soil that contained SCN was collected from Yichun and Daqing regions of Heilongjiang province in China. The cysts were dislodged from roots on nested sieves $(20$ mesh over 60 mesh $=$ $850-\mu \mathrm{m}$-pore sieve over 250 - $\mu \mathrm{m}$-pore sieve) with water spray. Each isolate was tested according to the method described using the original prescribed soybean differentials 'Pickett', 'Peking', PI 88788, and PI 90763. Lee 68 
was used as the susceptible control [28]. Seeds of the soybean differentials were germinated in vermiculite and transplanted singly into $7.5-\mathrm{cm}$-d clay pots when cotyledons opened. Each cultivar or line was transplanted into five pots. Plants were inoculated 2 days later with 4,000 eggs and second-stage juveniles in a $10-\mathrm{ml}$ suspension. All plants were grown in a greenhouse at $25-28^{\circ} \mathrm{C}$. Thirty days after inoculation, the cysts and females were collected and counted at each location. The index as used by Golden et al. (1970) was calculated as follows: $\mathrm{FI}=$ (Number of cysts and females on detected plant)/ (Average number of cysts and females on 'Lee68') $x$ 100. FI $>10$ was assigned "+" and FI $<10$ was assigned "_" [29]. According to the classification standards described by Riggs and Schmitt (1988), the soil collected from Yichun contained Hg Type 0 (SCN race 3) ('Peking' (female index; FI 2\%), 'PI 88788' (FI 3\%), 'PI 90763' (FI 1\%) and 'Pickett' (FI 3\%) were used as the standard differentials). The soil collected from Daqing contained a Hg Type.3.- (SCN race 14) (The cultivar 'Hutcheson' was used as the susceptible control while Peking (FI 98\%), PI 88788 (FI 3\%) and PI 90763 (FI 101\%) and Pickett (FI 68\%) were used as the standard differentials to determine the race classification (HG Type)).

\section{Female index determination of population}

Each line of the RILs was treated as above in the greenhouse at a temperature of $25-28^{\circ} \mathrm{C}$ and the record for the number of cysts and female of each line was as the same as above. Each recombinant inbred line (RIL) for each treatment contained five plants. A complete randomized design was used with three replicates. Each experiment was repeated twice.

\section{SSR marker detection}

Genomic DNA was isolated from leaf samples according to the procedures described by $\mathrm{Yu}$ et al. (1999) [30]. PCR amplifications were performed in 96-well micro titer plates using the PTC-100TM thermal cycler. Oligo nucleotide sequences were contributed by USDA-ARS Plant Genome Program, Cornell University and Iowa State University (http://129.186.26.94/ssr.html). SSR PCR reactions were $20 \mu \mathrm{l}$ containing $2 \mu \mathrm{l}$ of genomic DNA $(25 \mathrm{ng} / \mu \mathrm{l}), 1.5 \mu \mathrm{l} \mathrm{MgCl} 2(25 \mathrm{mM}), 0.3 \mu \mathrm{ldNTP}$ mixtures $(10 \mathrm{mM}), 2 \mu \mathrm{l} 10 \times$ PCR buffer, $2 \mu \mathrm{l} \mathrm{SSR}$ primer $(2 \mathrm{uM}), 0.2 \mu \mathrm{l}$ Taq polymerase enzyme (10 units/

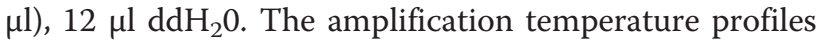
were as follows; $2 \mathrm{~min}$ at $94^{\circ} \mathrm{C}$, followed by 35 cycles of $30 \mathrm{sec}$ at $94^{\circ} \mathrm{C}, 30 \mathrm{sec}$ at $47^{\circ} \mathrm{C}, 30 \mathrm{sec}$ at $72^{\circ} \mathrm{C}$, then 5 min at $72^{\circ} \mathrm{C}$. After the PCR reaction, PCR products were mixed with loading buffer $(2.5 \mathrm{mg} / \mathrm{ml}$ bromophenol blue, $2.5 \mathrm{mg} / \mathrm{ml}$ diphenylamine blue, $10 \mathrm{mM}$ EDTA, and $95 \%(\mathrm{v} / \mathrm{v})$ formamide), denatured for $5 \mathrm{~min}$ at $94^{\circ} \mathrm{C}$ and then put on ice for $5 \mathrm{~min}$. The PCR products were separated by electrophoresis on a $6 \%(\mathrm{w} / \mathrm{v})$ denaturing polyacrylamide gel. Bands were directly detected after rapid silver staining [31].

\section{Data analyses}

Linkages among the markers were analyzed with Mapmaker 3.0b, using the Kosambi mapping function. WinQTLCart2.1 was used to detect QTL between marker intervals by permutations (permutations 300; significance level $<0.05)[32,33]$. The genetic linkage map was constructed by Mapchart 2.1 [34].

\section{QTL projected and chromosome location}

The locations of QTL were mapped on linkage groups and compared to those constructed in published studies. The markers that were polymorphic differed among studies. Therefore, in order to compare among QTL locations all relevant intervals were projected onto the GmComposite2003 map using the homothetic function $[35,36]$. The projection of QTL used the software BioMercator 2.1.

A local blastn search was performed to construct the gene map using a stringent BLAST search with a threshold E-values $\leq 1 \mathrm{e}-50$. A total of 1015 SSR markers together with 709 RFLP markers were used as the query sequences that were obtained from NCBI (http://www. ncbi.nlm.nih.gov), and the soybean genome sequences Glyma 1.0 were used as the database file (http://www. phytozome.net). A script Blastm.pl that was compiled by Perl language was developed for the construction of a gene map based on the search results. The QTL projected on GmComposite2003 computed previously were then projected onto this gene map based on the ratio of genetic distance and physical distance (about $412 \mathrm{kbp}$ per cM).

\section{Candidate gene detection}

A list of genes within the consensus QTL on this gene to physical map was generated using the genome annotation data. The structural features of nucleotide binding sites (NBS), leucine rich repeats (LRR), Toll/Interleukin1 receptors (TIR), and protein kinases (PK) were extracted from the InterProScan database and used as the domain list. Genes that contained those four domains were detected by using the hmmsearch program from the Hmmer software package [37]. For a further analysis, sequences with a similarity $>90 \%$ were inferred to have the coiled-coil (CC) domain by the Pepcoil program, and the transmembrane domain was predicted by the TM-HMMer program [38,39].

\section{Transcript abundance analysis}

In order to identify putative resistance genes for further analysis semi-quantitative RT-PCR was used to measure 
the transcript abundances. To quantify the relative amount of transcript accumulating for each of the genes and compare that between the resistance and susceptible cultivars, $1 \mu \mathrm{l}$ of the standardized cDNA was used in a $50 \mu \mathrm{l}$ PCR solution and cycled to within the predetermined linear amplification range. At 20 cycles before the end of the last cycle, primers for the gene encoding $\beta$-actin- 1 were added at the end of the $72^{\circ} \mathrm{C}$ extension phase. This would generate cDNA PCR products encoded by the target genes and the $\beta$-actin- 1 gene both within their linear amplification ranges. For confirmation a $2 \mu \mathrm{l}$ aliquot was sampled after each two cycles after 20. The PCR products were then separated by agarose gel electrophoresis, visualized on the $2 \%(\mathrm{w} / \mathrm{v})$ agarose and the band intensities compared [40].

\section{Acknowledgements}

This study was conducted in the Key Laboratory of Soybean Biology of Chinese Education Ministry and Soybean Development Centre of Agricultural Ministry, financially supported by National Core Soybean Genetic Engineering Project (Contract No. 2008ZX08004-002, 2009ZX08004-002B, 2009ZX08009-089B), Chinese National Natural Science Foundation (60932008, 30971810), National 973 Project (2009CB118400), Provincial Education Ministry for the team of soybean molecular design.

\section{Author details}

'Soybean Research Institute (Key Laboratory of Soybean Biology of Chinese Education Ministry), Northeast Agricultural University, Harbin, 150030, China. ${ }^{2}$ National Key Laboratory of Plant Molecular Genetics, Shanghai Institute of Plant Physiology and Ecology, Chinese Academy of Sciences, Shanghai, 200032, China. ${ }^{3}$ Department of Computer Science and Technology, Harbin Institute of Technology, Harbin, 150001, China.

\section{Authors' contributions}

WC carried out the QTL projected and chromosome location participated in the gene clone and drafted the manuscript. LD carried out the female index determination. ZW participated in the female index determination. $\mathrm{HH}$ carried out the SSR marker detection. YH participated in the design of the study and performed the statistical analysis. HZ, MG and WL conceived of the study, and participated in its design and coordination and helped to draft the manuscript. All authors read and approved the final manuscript.

Received: 2 January 2011 Accepted: 12 May 2011

Published: 12 May 2011

\section{References}

1. Messina MJ: Legumes and soybeans: overview of their nutritional profiles and health effects. Am J Clin Nutr 1999, 70(3):439s-450s.

2. Wrather JA, Sleper DA, Stevens WE, Shannon JG, Wilson RF: Cultivar and planting date effects on soybean stand, yield, and Phomopsis sp seed infection. Plant Dis 2003, 80(6):622-624.

3. Niblack TL, Wrather JA, Heinz RD, Donald PA: Distribution and virulence phenotypes of Heterodera glycines in Missouri. Plant Dis 2003, 87(8):929-932.

4. Liu PY: Advances in study of screening and utilization for antigen to soybean cyst nematode. Heilongjiang Agric Sci 2005, 6:44-47.

5. Wrather JA, Anand SC, Dropkin VH: Soybean cyst nematode control. Plant Dis 1984, 88(9):829-833.

6. Brucker E, Carlson S, Wright E, Niblack T, Diers B: Rhg1 alleles from soybean PI 437654 and PI 88788 respond differentially to isolates of Heterodera glycines in the greenhouse. Theor Appl Genet 2005, 111(1):44-49.

7. Concibido VC, Diers BW, Arelli PR: A decade of QTL mapping for cyst nematode resistance in soybean. Crop Sci 2004, 44:1121-1131.
8. Ruben E, Aziz J, Afzal J, Njiti VN, Triwitayakorn K, lqbal MJ, Yaegashi S, Arelli P, Town C, Meksem K, Lightfoot DA: Genomic analysis of the 'Peking' rhg1 locus: candidate genes that underlie soybean resistance to the cyst nematode. Molec Genet Genomics 2006, 276:320-330.

9. Arelli AP, Wrather JA, Anand SC: Genetic diversity among isolates of Heterodera glycines and sources of resistance in soybeans. Plant Dis 1992, 76(9):894-896.

10. Schmutz J, Cannon SB, Schlueter J, Ma J, Mitros T, Nelson W, Hyten DL, Song Q, Thelen JJ, Cheng J, Xu D, Hellsten U, May GD, Yu Y, Sakurai T, Umezawa T, Bhattacharyya MK, Sandhu D, Valliyodan B, Lindquist E, Peto M, Grant D, Shu S, Goodstein D, Barry K, Futrell-Griggs M, Abernathy B, Du J, Tian Z, Zhu L, Gill N, Joshi T, Libault M, Sethuraman A, Zhang X, Shinozaki K, Nguyen HT, Wing RA, Cregan P, Specht J, Grimwood J, Rokhsar D, Stacey G, Shoemaker RC, Jackson SA: Genome sequence of the palaeopolyploid soybean. Nature 2010, 463:178-183.

11. Arelli PR, Young LD, Mengistu A: Registration of high yielding and multiple disease-resistant soybean germplasm JTN-5503. Crop Sci 2006, 46:2723-2724.

12. Arelli PR, Pantalone VR, Allen FL, Mengistu A: Registration of Soybean Germplasm JTN-5303. J Plant Reg 2007, 1:69-70

13. Weisemann JM, Matthews BF, Devine TE: Molecular Markers Located Proximal to the Soybean Cyst Nematode Resistance Gene, Rhg4. Theor App/ Genet 1992, 85(2-3):136-138.

14. Concibido VC, Denny RL, Boutin SR, Hautea R, Orf JH, Young ND: DNA marker analysis of loci underlying resistance to soybean cyst-nematode (Heterodera glycines Ichinohe). Crop Sci 1994, 34:245-255.

15. Wu X, Blake S, Sleper DA, Shannon JG, Cregan P, Nguyen HT: QTL, additive and epistatic effects for SCN resistance in PI 437654". Theor Appl Genet 2009, 118(6):1093-1105.

16. Meksem K, Mitchum M, Lightfoot DA: Functional analyses of a candidate gene for resistance to soybean cyst nematode (Heterodera glycines) at the Rhg4 locus. BMC Genomics 2010.

17. Ude GN, Kenworthy WJ, Costa JM, Cregan PB, Alvernaz J: Genetic diversity of soybean cultivars from China, Japan, North America, and North American Ancestral Lines determined by amplifed fragment length polymorphism. Crop Sci 2003, 43:1858-1867.

18. Hu L, Lin W, Dong L, Ding X: Study on mathematical model of comprehansive factors for high yield of soybean cultivar Heinong37 under continuons cropping condition. Soybean Sci 1996, 15(2):130-135

19. Cregan PB, Jarvik T, Bush AL, Shoemaker RC, Lara KG, Kahler AL, Kaya N, VanToai TT, Lohnes DG, Chung J, Specht JE: An integratated genetic linkage map of the soybean genome. Crop Sci 1999, 39:1464-1490.

20. Kopisch-Obuch FJ, Diers BW: Segregation at the SCN resistance locus rhg1 in soybean is distorted by an association between the resistance allele and reduced field emergence. Theor Appl Genet 2006, 112(2):199-207.

21. Webb DM, Baltazar BM, Arelli PR, Schupp J, Clayton K, Keim P, Beavis WD: Genetic mapping of soybean cyst nematode race-3 resistance loci in the soybean PI 437.654. Theor Appl Genet 1995, 91:574-581.

22. Kazi S, Shultz J, Afzal J, Johnson J, Njiti VN, Lightfoot DA: Separate loci underlie resistance to root infection and leaf scorch during soybean sudden death syndrome. Theor Appl Genet 2008, 116(7):967-977.

23. Senda M, Jumonji A, Yumoto S, Ishikawa R, Harada T, Niizeki M, Akada S: Analysis of the duplicated CHS1 gene related to the suppression of the seed coat pigmentation in yellow soybeans. Theor Appl Genet 2002, 104(6-7):1086-1091.

24. Kabelka EA, Carlson SR, Diers BW: Glycine soja PI 468916 SCN resistance loci's associated effects on soybean seed yield and other agronomic traits. Crop Sci 2006, 46:622-629.

25. Melito S, Heuberger AL, Cook D, Diers BW, MacGuidwin AE, Bent AF: A nematode demographics assay in transgenic roots reveals no significant impacts of the Rhgl locus LRR-Kinase on soybean cyst nematode resistance. BMC Plant Biol 2010, 10:104-117.

26. Li YH, Zhang C, Gao ZS, Smulders MJM, Ma Z, Liu ZX, Nan HY, Chang RZ, Qiu LJ: Development of SNP markers and haplotype analysis of the candidate gene for $r h g 1$, which confers resistance to soybean cyst nematode in soybean. Mol Breeding 2009, 24:63-76.

27. Kanazin V, Marek LF, Shoemaker RC: Resistance gene analogs are conserved and clustered in soybean. Proc Natl Acad Sci USA 1996, 93(21):11746-11750. 
28. Riggs RD, Schmitt DP: Complete Characterization of the Race Scheme for Heterodera glycines. J Nematol 1988, 20(3):392-395.

29. Golden AM, Epps JM, Riggs RD, Duclos LA, Fox JA, Bernard RL: Terminology and identity of infra specific forms of the soybean cyst nematode (Heterodera glycines). Plant Dis 1970, 54:544-546.

30. Yu K, Park SJ, Poysa V: Abundance and variation of microsallite DNA sequences in beans (Phaseolus and Vigna). Genome 1999, 42:27-34.

31. Trigiano RN, Caetano-Anolles G: Laboratory exercises on DNA amplification fingerprinting for evaluating the molecular diversity of horticultural species. Hort Technol 1998, 8:413-423.

32. Lander ES, Green P, Abrahamson J, Baarlow A, Daly MJ, Lincoln SE, Newburg L: MapMaker: an interactive computer package for constructing primary genetic linkage maps of experimental and natural populations. Genomics 1987, 1:174-181.

33. Zeng Z: Theoretical basis of separation of multiple linked gene effects on mapping quantitative trait loci. Proc Natl Acad Sci USA 1993, 90:10972-10976.

34. Voorrips RE: MapChart: Software for the graphical presentation of linkage maps and QTLs. J Hered 2002, 93:77-78.

35. Song QJ, Marek LF, Shoemaker RC, Lark KG, Concibido VC, Delannay X, Specht JE, Cregan PB: A new integrated genetic linkage map of the soybean. Theor Appl Genet 2004, 109(1):122-128.

36. Arcade A, Labourdette A, Falque M, Mangin B, Chardon F, Charcosse A, Joets J: BioMercator: integrating genetic maps and QTL towards discovery of candidate genes. Bioinformatics 2004, 20(14):2324-2326.

37. Eddy SR: Profile hidden Markov models. Bioinformatics 1998, 14:755-763.

38. Lupas A, Van DM, Stock J: Predicting Coiled Coils from Protein Sequences. Science 1991, 252(5009):1162-1164.

39. Krogh A, Larsson B, Heijne GV, Sonnhammer ELL: Predicting transmembrane protein topology with a hidden Markov model: Application to complete genomes. J Mol Biol 2001, 305(3):567-580.

40. Yang Z, Woodahl EL, Wang XY, Bui T, Shen DD, Ho RJY: Semi-quantitative RT-PCR method to estimate full-length mRNA levels of the multidrug resistance gene. Biotechniques 2002, 33(1):196-203.

doi:10.1186/1471-2164-12-233

Cite this article as: Chang et al:: QTL underlying resistance to two HG types of Heterodera glycines found in soybean cultivar ' $L-10$ '. BMC Genomics 2011 12:233.

\section{Submit your next manuscript to BioMed Central and take full advantage of:}

- Convenient online submission

- Thorough peer review

- No space constraints or color figure charges

- Immediate publication on acceptance

- Inclusion in PubMed, CAS, Scopus and Google Scholar

- Research which is freely available for redistribution 